\title{
COMUNIDADE DE PRÁTICAS ACADÊMICAS E PARTICIPAÇÃO PERIFÉRICA LEGÍTIMA NA LICENCIATURA EM LETRAS: UM ESTUDOO DE CASO
}

\author{
Marcia Lisbôa Costa de OLIVEIRA \\ Universidade do Estado do Rio de Janeiro
}

RESUMO: O pressuposto deste trabalho é que o currículo da licenciatura em letras deve contemplar a participação dos alunos em atividades situadas que lhes permitam aprender, pelo exercício da participação periférica legítima (LAVE, 1993; LAVE \& WENGER, 1991, WENGER, 1998), as práticas socioculturais de escrita próprias ao Discurso acadêmico (GEE, 1990). Apresentaremos um estudo de caso que demonstra como a articulação entre iniciação à pesquisa, extensão e iniciação à docência propicia a interação em práticas sociais de referência na esfera acadêmica. Para isso, a participação ativa em projetos é fundamental, na medida em que as etapas neles desenvolvidas, bem como a produção científica deles decorrente, envolvem a ação dos alunos com/na linguagem e contribuem para a produção do conhecimento, numa progressão de complexidade das tarefas desempenhadas. Tendo em vista que as práticas constituem a comunidade e são por ela constituídas, participando periférica e legitimamente, o aluno constrói aprendizagens que permitirão sua participação plena na comunidade acadêmica. Essa ação com o acompanhamento de membros mais experientes é o primeiro movimento em direção à pertença ao grupo. Os resultados da pesquisa indicam que os iniciantes precisam não só ler e produção de textos científicos, mas também vivenciar eventos de letramento nos quais gêneros acadêmicos orais e escritos estejam imersos em atividades situadas. Tais práticas acadêmicas incluem a participação em encontros científicos, a redação de relatórios para agências de fomento e a publicação de artigos científicos em coautoria com o orientador, entre outras ações. Tais movimentos são fundamentais para a aprendizagem das condições de produção, circulação e recepção de textos científicos na área de letras, uma vez que, pela participação ativa e orientada nessa comunidade de práticas acadêmicas, os licenciandos aprendem de forma situada e significativa, enquanto constituem sua identidade como professores-pesquisadores.

Palavras-chave: discurso acadêmico; comunidade de práticas; aprendizagem situada.

\section{ACADEMIC COMMUNITIES OF PRACTICES AND LEGITIMATE PERIPHERAL PARTICIPATION IN LANGUAGE TEACHERS' EDUCATION: A CASE STUDY}

ABSTRACT: This paper's assumption is that undergraduate language teachers' education should include the participation of students in situated activities in order to learn sociocultural writing practices of academic discourse (GEE, 2008), by the exercise of legitimate peripheral participation (WASH, 1993; LAVE \& WENGER, 1991 WENGER, 1998). We shall present a case study that shows how the relationship between initiation into research and initiation into teaching in a social inclusion project may promote students' interaction in social reference practices in the academic sphere. We argue that students active participation in such projects is crucial, as, in the sequence of phases that must be developed, students are put into action in/with language, producing knowledge, as they follow a progression of complexity of tasks. Given that the practices constitute the community and are constituted by it, participating in peripheric and legitimated tasks, students situated learning will progressively enable their full participation in the academic community. Learning-by-doing with experienced members of this community is the first move towards membership. The survey results indicate that beginners need to read and write scientific texts, and they must also experience literacy events in which oral and written academic genres are produced in situated interactions. This engagement in academic practices involves the presence at scientific meetings, the drafting of reports to funding agencies and the publication of scientific papers co-authored with the supervisor, 
among other actions. Such movements are fundamental to provide the conditions in which students may learn about the production, circulation and reception of scientific texts that publicizes language and literature researches. In this way, thought guided participation in this community of academic practices, undergraduates experiment situated and meaningful learning, as they built their identities as teacher-researchers.

Keywords: academic discourse; community of practices; situated learning.

\section{1 - Apresentação}

Este artigo apresenta resultados preliminares do projeto de pesquisa de pós doutorado intitulado "Multiletramentos e letramentos críticos em contextos periféricos: um estudo etnográfico acerca das percepções de alunos em situação de vulnerabilidade social e de professores em formação inicial", que está sendo desenvolvido na FFCHL/USP, sob supervisão da Professora Walkyria Monte-Mór e relaciona-se às discussões teóricas empreendidas pelo Grupo de Pesquisa "Linguagem e Sociedade" (UERJ-FFP/CNPQ)

Neste trabalho, discutiremos os pressupostos, as estratégias e alguns resultados do projeto de extensão, iniciação científica e iniciação à docência "Letrajovem - Oficinas de Leitura e escrita para jovens e adultos em situação de vulnerabilidade social", desenvolvido na Faculdade de Formação de Professores de São Gonçalo (UERJ/ FFP), no que concerne ao letramento acadêmico e â profissionalização docente de licenciandos do curso de Letras dessa instituição, com foco na formação de professores-pesquisadores.

$\mathrm{Na}$ pesquisa cujos resultados parciais são aqui apresentados, partimos do conceito de participação periférica legítima em comunidades de prática, desenvolvido por Jean Lave e Etiene Wenger (1991), que propuseram um novo olhar ao repensar a aprendizagem em termos sociais, históricos e culturais. Articulamos tal proposição à abordagem dos novos estudos do Letramento (GEE, 2008; STREET, 2003 e 2014) acerca dos letramentos sociais, que inclui o letramento acadêmico como uma forma socioculturalmente construída de lidar com a escrita e à noção de habitus desenvolvida por Pierre Bordieu (2009).

O trabalho está dividido em quatro segmentos. Inicialmente, apresentaremos o contexto da pesquisa-ação desenvolvida no projeto. A seguir, embora o foco deste trabalho seja a aprendizagem situada das práticas acadêmicas de leitura e escrita, consideramos fundamental para a compreensão do enquadramento da pesquisa a apresentação das estratégias de iniciação à docência vivenciadas no cotidiano do Letrajovem. Sendo assim, refletiremos sobre os fundamentos teóricos que nos orientam na construção de estratégias de iniciação à docência a partir de um diálogo entre os conceitos de habitus e participação periférica legítima e apresentaremos brevemente a Metodologia Sociocultural Letrajovem que está sendo desenvolvida coletivamente no campo e transpõe didaticamente as teorias estudadas pela equipe do projeto. A reflexão sobre os aspectos teóricos-metodológicos das práticas desenvolvidas no projeto gerou a participação da equipe em eventos científicos da comunidade acadêmica interna e externa à instituição. Estudaremos a participação dos licenciandos em práticas de escrita em situação reais de interação nesses eventos acadêmicos e analisaremos a produção de textos dos gêneros "resumo científico" e "pôster", procurando demonstrar como a progressão das tarefas possibilitadas de forma orientada é fundamental para que os membros iniciantes progridam em direção às práticas de letramento acadêmico que representam a participação plena nesse grupo.

Nossas considerações finais apontam, sobretudo, para aspectos identitários que atravessam o movimento de aprender-fazendo a ser professor-pesquisador pela participação ativa na comunidade de práticas dos professores-pesquisadores, que se movimentam na interseção entre a docência e a pesquisa acadêmica. 


\section{2- $O$ contexto da pesquisa}

O Projeto Letrajovem é uma ação de inclusão social desenvolvida pela parceria entre a Universidade do Estado do Rio de Janeiro e outras duas instituições estaduais: o Tribunal de Justiça do Estado do Rio de Janeiro, através do Departamento de Inclusão Social (DEAPE/TJERJ), e o Centro de Recursos Integrados de Atenção ao Adolescente de São Gonçalo (CRIAAD/SG). Essas parcerias definem os dois grupos de adolescentes, jovens e adultos que participam do projeto.

No DEAPE/TJRJ, o público é composto por adolescentes, jovens e adultos em situação de vulnerabilidade social, participantes de programas de inclusão que atendem aos seguintes grupos: (1) jovens de 16 a 24 anos que cometeram ato infracional e cumprem, ou já concluíram, medida socioeducativa de semiliberdade ou liberdade assistida; (2) jovens de 18 a 24 anos oriundos de famílias de baixa renda ou em situação de risco social; (3) pais e mães de famílias em risco social e (4) egressos do sistema penitenciário. As oficinas semanais, com duas horas de duração, atendem a cerca de quarenta pessoas, em dois grupos.

No CRIAAD/SG, que é uma das unidades de semiliberdade que compõem o Novo DEGASE - Departamento Geral de Ações Socioeducativas, vinculado à Secretaria de Estado de Educação do Rio de Janeiro, são abrigados periodicamente 36 adolescentes que cumprem medida socioeducativa. Tendo em vista as peculiaridades desse grupo e as rotinas institucionais, realizam-se duas oficinas semanais, com duração de noventa minutos, para 5 a 7 adolescentes, agrupados por nível de escolaridade.

No que concerne à formação profissional dos alunos do curso de Letras, interliga-se teoria e prática, promovendo a discussão de pressupostos teóricos estudados nas disciplinas, nas reuniões técnicas do projeto e no grupo de pesquisa Linguagem e Sociedade. Tais conceitos fundamentam a elaboração de estratégias e material didático adequados às peculiaridades dos grupos de adolescentes, jovens e adultos que frequentam as oficinas. Estes, em sua maioria, são falantes de variantes linguísticas de menor prestígio social e apresentam grande defasagem em relação às expectativas de aprendizagem previstas para o nível escolar em que se encontram.

O projeto configura um campo de pesquisa-ação que articula extensão, iniciação à docência, e iniciação científica, de modo que a vivência profissional é propiciada de forma gradual, integrada e orientada. Para tanto, a prática desenvolvida no Letrajovem inclui a pesquisa teórica, a transposição didática, a ação pedagógica, a reflexão e a produção científica, tendo como foco o desenvolvimento da profissionalidade docente dos licenciandos como professores-pesquisadores.

A equipe do projeto é constituída atualmente por 5 bolsistas (um de iniciação à docência, dois de iniciação científica, um extensão e um de estágio interno complementar), quatro voluntários e uma docente, professora adjunta da instituição.

\subsection{A iniciação à docência no Letrajovem: aprendizagem-na-ação}

A fundamentação teórica do projeto Letrajovem situa-se no campo dos estudos do letramento desenvolvidos nas últimas décadas do século $\mathrm{XX}$, quando uma mudança paradigmática crítica gerou a revisão de posturas etnocêntricas no que tange às relações que os diferentes grupos sociais estabelecem com cultura escrita e buscou refletir acerca das implicações da abordagem sociocultural dos letramentos no contexto educacional.

Assim, de acordo com a linha de pesquisa do grupo Linguagem e Sociedade da qual fazemos parte, articulamos três conjuntos de concepções: (1) os chamados Novos Estudos do 
Letramento (GEE, 1990; STREET, 2003), notadamente as ideias de STREET acerca das relações de poder implicadas nos projetos de letramento; (2) as concepções da New London School (1996; COPE \& KALANTZIS, 2000 e 2009) sobre os multiletramentos, tanto no sentido da diversidade sociocultural, quanto no que se refere aos novos modos de conhecer e à reconfiguração da concepção de cidadania diante da entrada em cena das novas tecnologias da informação e comunicação e (3) a perspectiva dos letramentos críticos, que retoma e aprofunda na contemporaneidade a pedagogia Freireana (FREIRE, 1983; MORGAN, 1997).

Assim, entendemos que a percepção das múltiplas formas de conceber e utilizar a escrita e os modos de produzir sentidos emergentes na sociedade do conhecimento trazem aos educadores o desafio de reinventar suas práticas, sobretudo porque os NEL desvelam processos de aculturação encapsulados nos programas de educação linguística que concretizam modelos de letramento autônomos e dominantes (STREET, 2014) e põem em relevo a imposição exercida por pedagogias de dominação/subalternização (ARROYO, 2013 e 2014), inadequadas à diversidade contemporânea.

Para desconstruir posturas excludentes, que reforçam os mecanismos de opressão, é preciso mudar as concepções, antes das metodologias e das ferramentas, para isso, faz-se necessário mudar, entre outros aspectos do sistema, aquele que lhe é mais basilar: a formação dos educadores. Além disso, é importante entender o que pensam como compreendem os processos educativos que vivenciam os participantes das oficinas, como sujeitos que vivem situações periféricas.

Cada ciclo de trabalho se articula em quatro facetas interligadas, conforme demonstra a figura 1:



Figura1 - Ciclo de formação/profissionalização no projeto Letrajovem.

Os processos de desconstrução de práticas cristalizadas e de (re)construção da identidade docente se desenvolvem no ciclo representado acima, no qual atentamos continuamente ao que pensam, dizem e fazem os licenciandos, como sujeitos do seu ensinaraprender (ARROYO, 2013). A meta é desconstruir modelos de ação baseados na tradição transmissiva e construir novos parâmetros de atuação docente numa abordagem dialógica e interacionista.

Observamos que a prática reflexiva desenvolvida no projeto estimula o estabelecimento de um compromisso com as classes sociais mais desfavorecidas. Dessa forma, a identidade 
profissional em construção é permeada, desde a formação inicial, pelo reconhecimento da diversidade cultural e pela busca da justiça social.

No tocante à relação teoria e prática, parece unânime no campo da formação de docentes a ideia de que a prática deve ser propiciada de forma gradual, integrada e distribuída ao longo de todas as atividades realizadas durante o curso e não apenas como aplicação de princípios teóricos em situações concretas no momento do estágio supervisionado. De acordo com Bordieu $(2009$, p. 133) a prática é encarada quase sempre negativamente em sua dimensão mecânica como algo repetitivo e sem reflexão. E, quando estabelecemos uma relação de subordinação da prática à teoria deixamos de considerar toda a riqueza que encerra uma atividade prática em seus desdobramentos e estratégias de ação.

Bordieu, ao discutir o habitus, exemplifica a suas ideias através da análise da forma como cada profissional entende o seu campo de trabalho e constrói o que denominou de senso prático para uma atuação eficiente e produção dos resultados esperados. Podemos transpor esses ensinamentos para o entendimento da urgência de se conseguir realizar uma prática pedagógica com base em um referencial que possibilite ao professor entender o jogo que está sendo jogado de forma a permitir a seu aluno antecipar sua atuação quando estiver diante de uma situação prática e real. No caso da formação para a docência, os licenciados deveriam, portanto, ter a oportunidade de aprender a ser professores desempenhando tarefas individuais e coletivas aprendendo-pelo-fazer (learning-by-doing, LAVE e WENGER, 1991), como pessoasagindo-em-um-cenário (persons-acting-in-setting, CHAIKLIN e LAVE, 1993) que vivenciam a participação periférica legítima, mediada por um membro experiente da comunidade docente (LAVE e WENGER, 1991), conceitos que desenvolveremos no item 3 deste trabalho.

\section{2 - Metodologia sociocultural Letrajovem - um ensaio de transposição didática}

O problema da transposição didática é fundamental na articulação de qualquer proposta metodológica, uma vez que a prática de ensino implica em uma transformação do objeto, que é modalizada pelas estratégias pedagógicas adotadas. Bronckart afirma que a especificidade da didática das disciplinas escolares é focalizar "os saberes e as condições de sua transmissão, apropriação e transformação dos sistemas didáticos, em suas palavras, é preciso "identificar os múltiplos saberes de referência, os que são pertencentes, legítimos e eficazes para a organização de um programa de ensino articulado com o projeto de formar cidadãos competentes, donos de seu destino /.../" (2007, p.103)

Dentre os desafios didáticos enfrentados na construção das práticas pedagógicas desenvolvidas no Letrajovem, destacamos a tensão entre incorporar a diversidade sociocultural e linguística como elemento estruturante das oficinas e garantir o acesso a formas linguísticas e culturais mais valorizadas socialmente. Buscamos, então, nas teorias o suporte para nossas práticas de ensino.

O eixo metodológico funda-se sobre a ideia de que diferentes grupos sociais acionam repertórios linguísticos, culturais, procedimentais e éticos particulares, os quais, tratando-se da linguagem-em-ação, corporificam-se não só na escolha dos modelos de gêneros discursivos atualizados em suas produções textuais orais e escritas, mas, talvez em maior grau, na variações de temática, estilo e composição que configuram a relativa estabilidade de tais modelos (BAKHTIN, 2011; BRONCKART, 2010), conforme discutiremos mais adiante.

Ao pensarmos nos modelos de gêneros construídos/acionados/atualizados pelos membros de uma dada comunidade de práticas (Lave e Wenger, 1991), ou seja um grupo de pessoas que compartilha um objetivo, interesse ou necessidade comum e se engaja em um 
processo de aprendizagem coletiva, não podemos desvinculá-los de uma densa superposição de camadas.

Os Discursos incorporados/construídos/negociados pelos participantes representam modos-de-ser-no-mundo (GEE, 2008) que se refletem também no engajamento em práticas e eventos de letramento peculiares ao cotidiano do grupo (BARTON e HAMILTON, 2000).

Nesse sentido, as práticas de letramento correspondem a discursos, construções e concepções que são, simultaneamente, pessoais e compartilhadas por grupos sociais, sendo reguladas por regras sociais que determinam a produção, o uso, a distribuição e o acesso aos textos. Dessa maneira, os sentidos que uma dada comunidade de práticas atribui à escrita configuram os modos como esta se situa naquele contexto sociocultural.

As relações de poder fazem com que as concepções de letramento conformem um território de conflito em que as forças são desiguais, pois grupos dominantes tendem a impor suas concepções sobre os demais, sendo a escola um cenário em que esse tipo de imposição ocorre com frequência. No conjunto social, portanto, um problema que chama à atenção é o fato de que a pertença a uma comunidade de práticas e a incorporação de um Discurso - na medida em que estes integram, dividem e categorizam grupos na sociedade - está diretamente relacionada à distribuição de bens culturais e materiais decorrente do poder que os grupos detêm. (GEE, 2008)

Dessa forma, entrelaçando os conceitos de letramento e comunidades de práticas como fundamentos da metodologia desenvolvida, o projeto Letrajovem assume a perspectiva defendida por Menezes de Souza e Monte Mor (2006, p. 108), considerando que:

\footnotetext{
/.../a nova concepção de heterogeneidade da linguagem e da cultura, que promove os conceitos de "letramento" e de "comunidade de prática", também prevê a heterogeneidade de saberes e conhecimentos diferentes existentes em cada comunidade de prática. Esses saberes e conhecimentos heterogêneos estão presentes nas diversas formas de letramento como práticas socioculturais. Abrir a sala de aula para essas heterogeneidades significa transformar o caráter excludente da escola.
}

O reconhecimento do direito à diferença e a luta contra a discriminação e a desigualdade social nos inspiram para lidarmos com grupos encharcados de diversidades, tentando promover relações dialógicas e igualitárias, sem neutralizar os conflitos inerentes a esta realidade ou ignorar as relações de poder presentes nas relações sociais e interpessoais que ocorrem em sala de aula. Ao contrário, o exercício constante da crítica nos leva a construir e reconstruir estratégias adequadas para o enfrentamento dos conflitos que são constantemente encenados nas aulas.

A relação entre o letramento escolar e os letramentos sociais se faz sobre um tênue equilíbrio, que pode sempre pender para a dominação sinalizada por ARROYO (2013). Por isso, o risco de assumir posturas contraditórias nos faz ficarmos vigilantes, evitando acionar processos de aculturação, que podem se infiltrar silenciosamente nos programas de educação linguística, quando se concretizam de modelos de letramento autônomos e dominantes. Tais modelos baseiam-se no "texto dissertativo em prosa ocidental e acadêmico" (STREET, 2014, p. 44) e adotam uma visão descontextualizada do letramento, tratando-o como habilidade neutra e técnica. Dessa forma, tendem a realizar o inverso do que pretendemos no projeto Letrajovem, pois se tornam pedagogias de dominação/subalternização (ARROYO, 2013).

Refletindo sobre a natureza ideológica das relações de poder que perpassam as práticas letradas (STREET, 2014), procuramos respeitar a diversidade sociocultural, estando conscientes de que os movimentos de ampliação e reconfiguração de repertórios que 
desencadeamos irão, inevitavelmente, impactar as identidades dos participantes das oficinas, já que as identidades são móveis e se fazem e refazem nas interações.

O objetivo pedagógico do Letrajovem, portanto, é a implementação de um modelo ideológico de letramento (STREET, 2014) que reconheça o fato de que as práticas de leitura e escrita são sempre encharcadas de significados culturais, bem como de concepções ideológicas sobre o que é considerado letramento e, portanto, estão marcadas pelas relações de poder decorrentes dessa definição.

Dessa forma, precisamos evitar estabelecer a priori o que conta como letramento ou uma cultura letrada padrão, o que configura um desafio para a equipe, uma vez que não pertencemos ao grupo social alvo das oficinas e nossas concepções acadêmicas e culturais tendem a validar certas práticas de leitura e escrita e a definir cânones.

No trabalho constante de reflexão sobre a prática que desenvolvemos desde o início do projeto, chegamos à configuração atual das etapas em que organizamos o trabalho pedagógico em cada módulo das oficinas. Chamamos de módulo uma sequência didática que articula tema e gênero textual, e que tem duração variável dependendo das dificuldades ou facilidades apresentadas pelo grupo e do interesse que o tema lhes desperta.

Usamos a metáfora da natação para facilitar a compreensão das três etapas pelos participantes, pois, como se trata de uma pesquisa-ação, é fundamental que eles compreendam o que se faz e colaborem com a construção da proposta. Por isso construímos uma espécie de metametodologia, explicitando em todas as atividades a etapa e os objetivos de cada estratégia.

Essa perspectiva foi se tornando clara progressivamente e as experiências têm demonstrado o aumento do compromisso, tanto da equipe do projeto, quanto dos participantes das oficinas. Constatamos, que na medida em que compreendem a metodologia, o acesso à compreensão orgânica do processo pedagógico facilita a construção do conhecimento na interação para tods os membros da comunidade de práticas que se configura no projeto.

Os módulos temáticos são estruturados em uma sequência das etapas que propõem, respectivamente: (1) Mergulho no tema - (Re)organizar referências pessoais sobre o tema discutido no módulo; (2) Aprofundamento no gênero - sistematizar conhecimentos sobre temática, construção composicional e estilo de um gênero textual; (3) Afloramento de ideias e de linguagem - produzir textos escritos sobre o tema discutido no módulo, atualizando a estrutura do gênero estudado de acordo com uma situação de interação proposta.

Temos procurado trabalhar constantemente a reflexão acerca de nosso lugar, como professores, de modo que sejamos capazes de agir como mediadores num contexto dialógico e, para isso, precisamos ultrapassar o padrão tradicional da fala durante a aula, centrada no professor, cujo status superior é naturalizado (MORGAN, 1997, p. 117). Numa aula convencional, observam-se sequências do tipo pergunta-resposta-avaliação ou ainda situações em que os alunos são encaminhados, através de um processo semelhante à adivinhação, para a resposta correta, que é controlada pelo professor. Assim, os alunos respondem dentro do enquadramento fornecido por quem detém o poder nessa cena discursiva e a sala de aula, assim organizada, acaba por configurar uma comunidade de desiguais (MORGAN, 1997, 131).

Esse processo de transformação do papel de centro do ensino para o de mediadores tem se mostrado muito difícil para os professores em formação, habituados a um modelo de docência que não costuma permitir a emergência de vozes e subjetividades. Assim, aprendemfazendo a mediar o movimento coletivo de produção do conhecimento nas oficinas, construir 
junto com os alunos, criticamente, os sentidos dos textos e do mundo. Isso significa assumir que:

\begin{abstract}
A co-laboração, como característica da ação dialógica, que não pode dar-se a não ser entre sujeitos, ainda que tenham níveis distintos de função, portanto, de responsabilidade, somente pode realizar-se na comunicação. O diálogo, que é sempre comunicação, funda a colaboração. /.../ $\mathrm{O}$ diálogo não impõe, não maneja, não sloganiza. (FREIRE, 1983, p.1)
\end{abstract}

Nas interações, ultrapassamos a ideia de compreensão como um conjunto de habilidades neutras e, sob a perspectiva dos letramentos críticos, baseamo-nos nos seguintes princípios: (1) desafiar concepções e valores do senso comum; (2) explorar múltiplas perspectivas e imaginar aqueles que estão ausentes ou são silenciados nos textos lidos; (3) examinar relacionamentos, particularmente aqueles que envolvem diferenças de poder; (4)refletir sobre e usar as práticas de letramento para agir em prol da justiça social. (LEWISON, FLINT e VAN SLUYS, 2002, apud ONTARIO MINISTRY OF EDUCATION, 2009.)

Partimos da ideia de que o processo de emancipação implica a palavra-ação, pois "a palavra verdadeira que é trabalho, que é práxis, é transformar o mundo, dizer a palavra não é privilégio de alguns homens, mas direito de todos os homens". (FREIRE, 1983, p.96) Assim, as oficinas são concebidas como espaços de pronúncia do mundo.

\title{
3 - A iniciação científica no Projeto Letrajovem: participação periférica legítima e aprendizagem situada
}

A participação em situações reais de ação/interação, sob orientação de um profissional experiente é uma forma tradicional de aprendizagem em diferentes profissões. Na carreira acadêmica, no entanto, é comum a ideia de que o aluno deve aprender por si mesmo a utilização eficiente das práticas que são valorizadas nesse contexto. Essa concepção é bastante equivocada, no entanto, pois aprender o Discurso acadêmico implica não só o reconhecimento e o domínio dos usos da escrita nesse universo, mas também a aprendizagem das distintas formas como a linguagem é usada nos campos disciplinares, que possuem peculiaridades no que tange aos usos dos textos, além dos comportamentos e valores compartilhados pelo núcleo dessa comunidade e por seus membros em diferentes posições.

Pensar a comunidade de práticas como um espaço de cognição situada significa incorporar uma concepção de aprendizagem que não se esgota na mera internalização de conhecimentos, mas está ligada à incorporação de um Discurso, no sentido que James Paul Gee atribui a esse termo.

A equipe do projeto Letrajovem forma uma comunidade de práticas que se reúne em torno de um empreendimento comum e um engajamento mútuo em uma prática social bastante específica e compartilha um repertório comum de práticas e rotinas. (LAVE e WENGER, 1991)

Podemos observar nesse grupo formado por licenciandos e professora, as três principais características de uma comunidade de práticas:

a) O domínio de interesse e competência compartilhada: ensino de língua e literatura com foco na justiça social, compromisso que os distingue dos demais licenciandos e professores, na medida em que estão mutualmente engajados na construção de estratégias pedagógicas e na sistematização das experiências bem sucedidas.

b) A comunidade: para dar conta das tarefas, os membros da comunidade Letrajovem unem-se em atividades, discussões e tarefas específicas, colaborando e 
relacionando-se de forma intensa, aprendem e ajudam uns aos outros a aprender. As redes sociais e os meios de comunicação digitais são utilizados quase diariamente pelo grupo, que compartilha também interesses que ultrapassam a participação no projeto.

c) A prática: a equipe do projeto desenvolveu ao longo dos dois anos de trabalho comum um repertório de recursos, experiências, conceitos e ferramentas. A interação semanal nesse período construiu um ligação entre os licenciando de tal ordem que temos hoje como voluntários alunos que, mesmo após a conclusão do curso, trabalhando, cursando pós graduação lato e strictu senso, continuam como voluntários no Letrajovem. Essa comunidade renova-se com a entrada de novatos, que iniciam sua participação já contando com o apoio do grupo coeso. A solidariedade nas práticas enriquece o ambiente de aprendizagem construído e criam uma rede sólida de aprendizagem.

A aprendizagem situada nessa comunidade de práticas ocorre paralelamente ao processo de entrada dos licenciandos na comunidade acadêmica, em que o professor assume o papel de membro mais experiente que guia os noviços, da mera observação à participação periférica que ele legitima, tendo como meta a participação plena. Esse processo foi sintetizado no esquema abaixo:

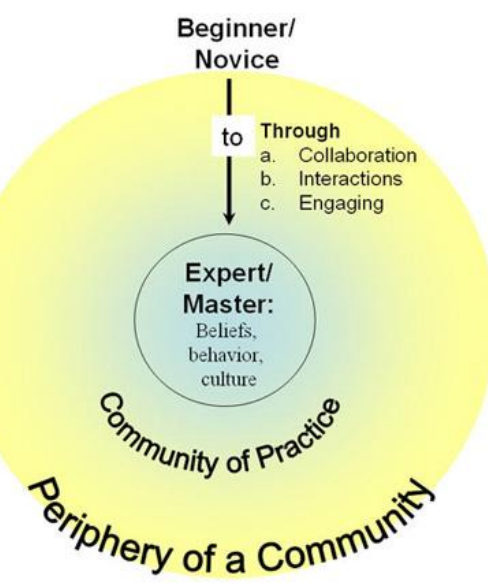

Figura 2 - Aprendizagem em comunidades de práticas ${ }^{1}$

Entrar na comunidade acadêmica significa aprender a usar os gêneros em circulação nesse contexto, dos mais simples, aos mais complexos. O primeiro passo é a elaboração de resumos acadêmicos para submissão à comissão organizadora de eventos científicos, a seguir, podemos considerar a apresentação de pôsteres e comunicações até chegar à redação de artigos para periódicos em co-autoria ou sob orientação do professor, rumo à autoria autônoma.

A seguir, apresentaremos alguns exemplos de práticas periféricas desenvolvidas no processo de introdução dos licenciandos ao Discurso da academia. No trabalho em projetos acadêmicos reais, destacaremos alguns exemplos dos gêneros resumo científico e pôster, os quais demonstram a progressão do letramento acadêmico dos licenciandos e de seu ingresso na comunidade científica da área.

Ao pensarmos nos modelos de gêneros construídos/acionados/atualizados pelos membros de uma dada comunidade de práticas (LAVE e WENGER, 1991), ou seja um grupo de pessoas que compartilha um objetivo, interesse ou necessidade comum e se engaja em um processo de aprendizagem coletiva, não podemos desvinculá-los de uma densa superposição de

\footnotetext{
${ }^{1}$ https://johnmill.wordpress.com/2010/04/10/visualisations-of-learning/
} 
camadas. Na figura abaixo, procuramos demonstrar a imbricação que se opera nas esferas sociointeracionais e demarca as comunidades de práticas:

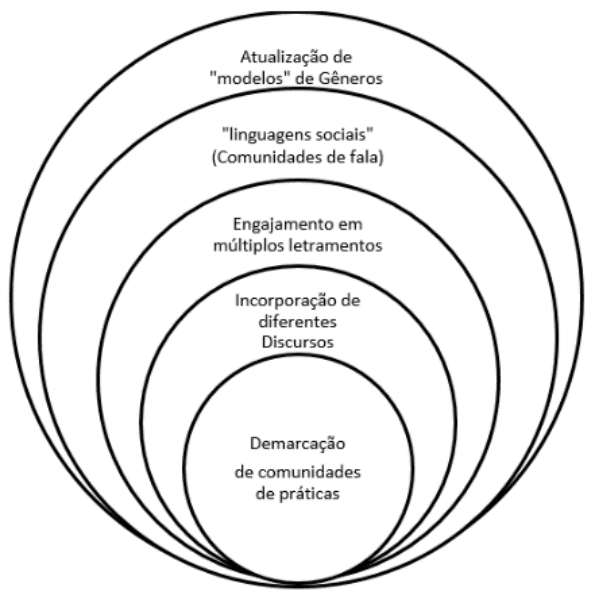

Figura 3 - Linguagem, discursos e comunidades de práticas.

A figura ilustra as diferentes dimensões que se superpõem e se entrelaçam na demarcação de uma comunidade de práticas. Os Discursos incorporados/construídos/negociados pelos participantes representam modos-de-ser-no-mundo (GEE, 2008) que se refletem também no engajamento em práticas e eventos de letramento peculiares ao cotidiano do grupo (BARTON e HAMILTON, 2000).

Nesse sentido, as práticas de letramento correspondem a discursos, construções e concepções que são, simultaneamente, pessoais e compartilhadas por grupos sociais, sendo reguladas por regras sociais que determinam a produção, o uso, a distribuição e o acesso aos textos. Conforme os autores, as práticas de letramento constituem as maneiras como diferentes culturas usam a escrita, enquanto os eventos de letramento configuram situações concretas de interação em que a escrita tem um papel central, embora possa haver também a presença de interlocução oral. Esta noção de evento está relacionada à natureza situada do letramento e demarca a relação deste com o contexto, ressignificando a perspectiva Bakhtiniana segundo a qual a análise da língua falada deveria partir de eventos sociais de interação verbal. (BARTON e HAMILTON, 2000, p. 7)

Dessa maneira, os sentidos que uma dada comunidade de práticas atribui à escrita configuram os modos como esta se situa naquele contexto sociocultural. As relações de poder fazem com que as concepções de letramento conformem um território de conflito em que as forças são desiguais, pois grupos dominantes tendem a impor suas concepções sobre os demais, sendo a escola um cenário em que esse tipo de imposição ocorre com frequência. No conjunto social, portanto, um problema que chama à atenção é o fato de que a pertença a uma comunidade de práticas e a incorporação de um Discurso - na medida em que estes integram, dividem e categorizam grupos na sociedade - está diretamente relacionada à distribuição de bens culturais e materiais decorrente do poder que os grupos detêm. (GEE, 2008)

A elaboração do gênero resumos acadêmico demanda capacidade de articular conceitos teóricos com clareza e concisão em uma estrutura bastante convencional regulada. Na experiência aqui discutida, os primeiros resumos foram elaborados pela professora, com a participação dos licenciandos como observadores. Tratava-se, então, da apresentação da base teórica do projeto em um evento interno da universidade, em 2014. Essa primeira produção, embora situada em uma prática real, pode ser considerada menos do que periférica, no sentido de que os iniciantes não agiram diretamente na produção dos textos. 
O resumo foi elaborado tendo em vista a participação na "UERJ sem Muros", evento interno que reúne todo os projetos de extensão, iniciação à docência, iniciação científica e estágio interno complementar realizados na instituição, foi a primeira participação da equipe, incluindo a professora, nesse evento. O resumo, de curtíssima extensão, foi publicado nos Anais do evento e apresentou o seguinte texto:

\begin{abstract}
Letrajovem - oficinas de língua portuguesa para adolescentes e jovens em conflito com a lei

Resumo: O projeto Letrajovem é desenvolvido no âmbito do Departamento de Letras da FFP/ e oferece oficinas de Língua Portuguesa, com ênfase em leitura e produção de textos a adolescentes e jovens atendidos pelos programas de inclusão social do Departamento DEAPE/TRERJ e adolescentes que cumprem medida socioeducativa no CRIAAD/SG. Apresentaremos exemplos das práticas pedagógicas desenvolvidas nas oficinas, bem como análises dos textos produzidos pelos adolescentes, que não só revelam as dificuldades enfrentadas por esses sujeitos no que tange às competências leitora e escritora, mas também suas concepções e valores.
\end{abstract}

A aprovação dos três resumos submetidos, dentre os quais destacamos acima um exemplo, gerou a necessidade de organizarmos os pôsteres e sua apresentação. Tais tarefas, totalmente novas para os licenciandos, precisaram também de muito apoio da professora, que, como membro veterano da comunidade de práticas em que eles eram iniciantes, controlou a produção do gênero, ajustando-o ao que considerou adequado para o evento científico do qual participariam.

O tema do trabalho foi a relação entre teoria e prática, no momento em esboçava-se a configuração da metodologia do projeto. Nesse momento inicial do percurso, o resumo submetido foi pela professora e seguiu um padrão formatado e impessoal, como se pode verificar na transcrição acima. Nesse resumo, ocorre claramente o silenciamento das vozes dos licenciandos e a aparente neutralidade científica sinaliza que não houve, de fato, compartilhamento da autoria. Nessa atividade de produção escrita, os licenciandos foram, portanto, meros observadores. $\mathrm{O}$ pôster apresentado para a primeira participação da equipe no evento " $25^{\text {a. }}$ UERJ sem Muros" foi elaborado de forma mais compartilhada, sob orientação, e teve o seguinte layout:

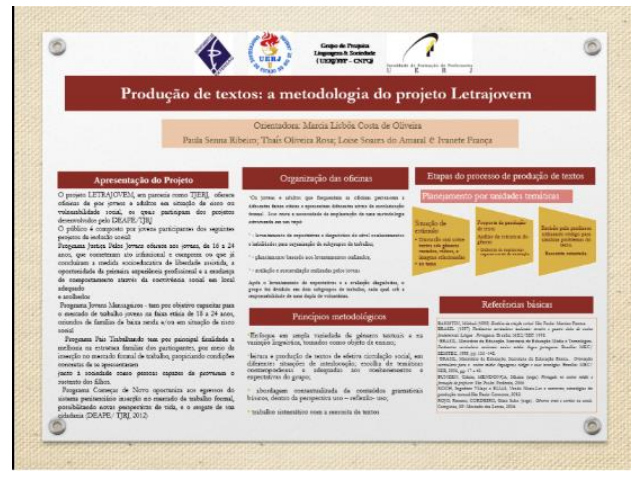

Figura 3 - Pôster para a " $25^{\text {a }}$. UERJ sem Muros"

Durante o evento, percebemos que, assim como ocorreu na redação do resumo, preparamos um pôster que, embora estivesse correto, não atendia exatamente à proposta do evento. Ainda assim, conseguimos uma excelente avaliação das apresentações, o mesmo ocorrendo em relação aos dois outros pôsteres, o que validou a concessão de três bolsas para o projeto, que nesse momento contava apenas com voluntários.

A análise dos pôsteres apresentados pelos outros participantes configurou um interessante corpus para o estudo sobre o gênero, tendo em vista a diversidade dos formatos presentes no que se refere à estrutura composicional, à temática e ao estilo. Observamos que, 
dependendo das características do estudo apresentado, apresentavam-se diferentes volumes de informações, sendo uma tendência dominante a diagramação atraente e o uso de imagens. Essas constatações, bem como a identificação da relevância do apoio das informações que figuram no pôster no momento da apresentação oral diante do avaliador do evento, que, no caso da USM, é crucial para a obtenção e a manutenção de bolsas para os estudantes, levaram-nos à revisão do modelo para as apresentações na USM no ano seguinte e em outros eventos dos quais participamos.

A seguir reproduzimos dois pôsteres sobre a Metodologia Sociocultural Letrajovem, os quais foram apresentados, respectivamente, no "V Simpósio Internacional de Gêneros Textuais" e na " $26^{\mathrm{a}}$. UERJ sem Muros", ambos em 2015. Em ambos podemos identificar a progressão do domínio do gênero pelos licenciandos:

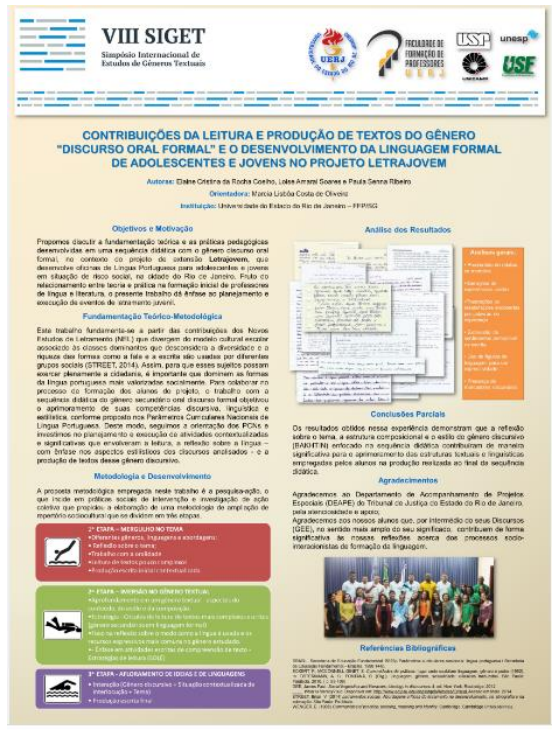

Figura 4 - Pôster apresentado no V SIGET, em 2015

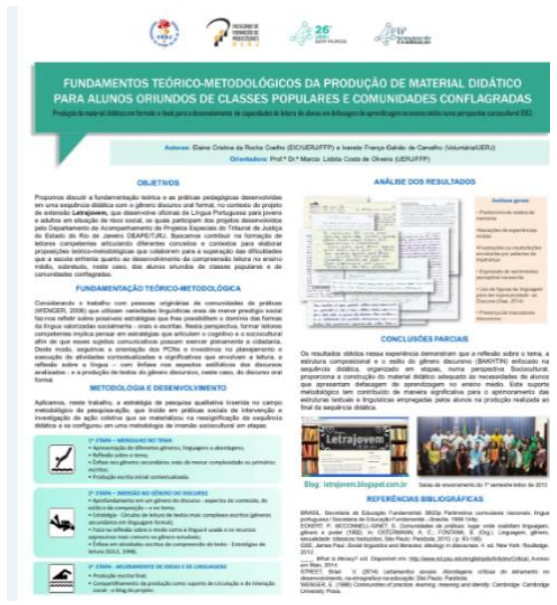

Figura 5 - Pôster apresentado na "26a . UERJ sem Muros", em 2015.

Consideramos importante mencionar que ambos os pôsteres serviram como apoio para apresentações muito bem sucedidas, tendo o segundo recebido "Menção Honrosa", por ter sido considerado um dos dez melhores trabalhos na categoria "Estágio Interno Complementar" apresentados na USM, que envolve toda a comunidade acadêmica da instituição.

Ao longo dos últimos três anos, a equipe participou de vários eventos científicos internos e externos à UERJ, apresentando trabalhos nos seguintes encontros acadêmicos: 
pôsteres nas semanas de letras da FFP/UERJ d 2014 e 2015; pôsteres nos encontros do rupo de Pesquisa Linguagem e Sociedade (UERJ-FFP/CNPQ) realizados em 2014 e 2015; comunicação coletiva no "Encontro Latino Americano de Educação de Jovens e Adultos em Situação de Restrição e Privação de Liberdade", em 2014; Pôsteres no "V Simpósio Internacional de Gêneros Textuais (USP) em 2015". Em 2016, já está a aprovada a participação de quatro trabalhos produzidos pelos licenciandos, dois individuais e dois em duplas no IV CIPLOM, que ocorrerá em Florianópolis.

Para demonstrar o quanto a participação nesses eventos colaborou para o desenvolvimento do letramento acadêmico dos licenciandos, selecionamos um resumo aprovado para apresentação no IV CIPLOM, que foi construído de forma autônoma pela aluna e a respectiva avaliação pelo parecerista:

\section{A PRODUÇÃO DO GÊNERO ARTIGO DE OPINIÃO COM ADOLESCENTES EM SITUAÇÃO DE SEMILIBERDADE}

O trabalho apresentado desenvolve-se no âmbito do projeto de extensão "LetraJovem" que oferece Oficinas de Língua Portuguesa aos adolescentes que cumprem medida socioeducativa em regime de semiliberdade no Centro de Recursos Integrados de Atenção ao Adolescente situado no Município de São Gonçalo (RJ) e do programa de inclusão social do Departamento DEAPE/TRERJ. Apresentaremos trabalhos realizados dentro da oficina com gêneros textuais, enfatizando o gênero artigo de opinião. Considerando as relações entre linguagem, cultura e sociedade, tomaremos como pressupostos as reflexões acerca dos gêneros discursivos para Gunther Kress (1989), e de acordo com seu olhar, os gêneros textuais constituem a identidade dos eventos sociais da instituição; no caso em questão, o CRIAAD/DEAPE/TRERJ, articulando essa discussão ao conceito de Discurso de James GEE (2005) e seus desdobramentos: os discursos primários e secundários. Os discursos primários são os que os indivíduos adquirem enquanto membros de uma comunidade específica, normalmente na família, já os discursos denominados secundários são aqueles que sofrem influência de outras esferas sociais como escolas, igrejas. A partir da análise de algumas das produções escritas pelos participantes do projeto, observamos o descumprimento das propostas de produção de texto que solicitam a elaboração de texto argumentativo, uma vez que grande parte dos adolescentes tende a redigir textos dos gêneros que compõem a esfera narrativa. Considera-se que isso ocorre visto que o ato de narrar é marcante no discurso primário de suas "comunidades de práticas" originárias, em outras palavras, seu discurso de origem familiar. Soma-se a isso o fato do regime semiprisional em que esses adolescentes são inseridos exigir, com certa frequência, depoimentos judiciais e outros tipos de relatos, o que os impele ainda mais à compreensão e ao exercício narrativo. Por fim, sabe-se que existe uma centralidade em textos argumentativos no contexto escolar, trazendo uma necessidade de aprofundamento nos gêneros textuais que acionam essa esfera discursiva.

Palavras-chave: argumentação; letrajovem; discurso; gênero textual; letramento.

O texto acima foi construído sem ajuda da professora e submetido através da plataforma do evento, os procedimentos descritos na primeira circular do mesmo. Para produzi-lo, a licencianda seguiu as regras e buscou ajustar-se aos critérios prescritos nessa circular ${ }^{2}$

CRITÉRIOS DE SELEÇÃO DOS RESUMOS

- Cada participante poderá submeter, no máximo, dois resumos à Comissão Científica.

- Os resumos deverão ser enviados pelo Formulário de Inscrição disponível na página do evento, com a extensão de no mínimo 250 palavras e no máximo 400, sem exceção.

- Os resumos devem conter: a) Título da apresentação: Nome(s) do(s) autor(es); c) Instituições a que se filiam os autores; d) cinco palavras-chave.

Os resumos enviados à Comissão Científica do III CIPLOM serão avaliados, considerando-se os seguintes critérios:

- Relação do trabalho com um dos eixos temáticos do evento.

\footnotetext{
${ }^{2}$ Disponível em: http://iiiciplomeaplom.webnode.com/circulares/
} 
- Natureza científico-profissional das posições, argumentos e proposições assumidos (o trabalho não pode ter caráter comercial).

- Relevância teórica e científica para as áreas do conhecimento contempladas pelo evento.

- Qualidade da organização textual (linguagem empregada, coesão, coerência, clareza).

- Clareza na exposição dos aportes teórico-metodológicos, dos objetivos e resultados do trabalho.

Observamos o caráter fortemente normatizado da escrita acadêmica nesse conjunto de prescrições, que configuram um modelo de gênero "resumo científico" bastante fechado. Uma vez que o atendimento à regulação do texto a ser produzido está relacionada à aprovação ou não do trabalho, pode-se considerar que este constitui um dos rituais de ingresso nessa comunidade de práticas. $\mathrm{O}$ poder dos membros mais experientes está expresso tanto nessas regras, quanto no controle do acesso ao grupo mediante a submissão a seus limites restritivos e reguladores. O termo "submissão" é bem revelador do processo de ajuste às normas que o iniciante experimenta ao produzir seu resumo, abrindo mão do estilo individual para adaptar-se às constrições de extensão e ao modelo predeterminado. No período de emissão das cartas de aceite e pedidos de ajuste, a licencianda recebeu a seguinte avaliação do parecerista anônimo:

O resumo contém os objetivos, métodos e procedimentos básicos, além dos principais
resultados e as conclusões mais relevantes da pesquisa com clareza e objetividade. Os
principais resultados e conclusões mais relevantes deste trabalho manifestam
compatibilidade com as temáticas e objetos de estudo do evento. Tendo em vista que
se trata de uma pesquisa de marcado cunho social, desenvolvida sob uma perspectiva
original e transcendente, sugiro que a autora revise o trabalho e inclua algumas
referências básicas sobre inclusão social, transformação através da linguagem,
produção textual -gênero artigo- e/ou expressão escrita em português como língua
materna. Em outras palavras, que a autora especifique as referências bibliográficas
que avalizam essa investigação e que lhe permitiram se aproximar do objeto de estudo
e desenvolver essa pesquisa.

Ao rever o texto para adequá-lo às expectativas do membro mais experiente que avaliou seu trabalho, a autora do resumo precisou ajustar o modelo de gênero ativado na produção inicial, considerando essa situação específica de interação. A revisão do resumo, configurou, portanto, um momento muito relevante em sua entrada nessa comunidade de práticas, no qual ela buscou a convergência com as práticas validades pelos membros mais experientes.

Consoante Bakhtin, os gêneros configuram modelos relativamente estáveis, o que é claramente observável na comunidade científica, pois cada evento define suas regras, de modo que suas exigências atualizam o modelo de forma peculiar. Por isso, na medida em que escrevem resumos e são avaliados por diferentes comitês científicos, os licenciandos desenvolvem a habilidade de adaptar seus conhecimentos sobre o gênero ao modelo esperado pelos interlocutores previstos, o que é muito diferente de redigir um trabalho para avaliação na universidade, para um determinado professor.

Entendemos que, ainda que analisados de forma breve, os exemplos apresentados podem demonstrar a importância da participação periférica legítima em práticas reais de produção de textos no contexto de eventos científicos, para a aprendizagem do Discurso e dos modos de escrita que caracterizam essa comunidade de práticas.

\section{4 - Considerações finais}

Os territórios de ação do projeto Letrajovem entrecruzam práticas d diferentes comunidades, entre as quais destacamos a comunidade Letrajovem, a comunidade das oficinas Letrajovem, a comunidade dos professores e a comunidade científica da área. Essas 
comunidades, como espaços de formação, impulsionam a equipe do projeto à reflexão, ao mesmo tempo que nos colocam em uma situação privilegiada para o desenvolvimento crítico e consciente de experiências pedagógicas voltadas para a justiça social.

Um dado importante para isso é nosso entrelugar em relação ao sistema escolar. Isso porque, embora trabalhemos em paralelo ao sistema escolar, na medida em que nossa meta é a permanência qualitativa ou o retorno dos participantes à escola, estamos fora desse sistema, ensinando-aprendendo em espaços diferenciados.

Essa situação nos permite liberdade para construir uma metodologia que ultrapassa as amarras do contexto escolar. Além disso, temos a possibilidade de nos aproximarmos mais dos adolescentes e jovens, estabelecendo rotinas e formas de convivência dialógica.

A autonomia pedagógica derivada dessa posição em relação ao sistema escolar é altamente favorável, na medida em que nos permite exercitar a transposição didática e, em processos de ensaio e erro, ajustar permanentemente nossas práticas e concepções. Isso nos tem liberado para viver o ensinar-aprender de que nos fala ARROYO (2013), usando criatividade pedagógica para construir uma metodologia ancorada em quatro pilares: (1) ênfase em gêneros textuais; (2) presença de diferentes linguagens, (3) educação pautada em valores e no respeito à diversidade (4) perspectiva sociocultural.

Uma aspecto privilegiado no projeto é a iniciação à docência. Nesse aspecto, Miguel ARROYO nos alerta para o fato de que é preciso incorporar à formação dos licenciandos a reflexão sobre as vivências extremas das crianças e adolescentes nas periferias, capacitando-os para trabalhar nos limites da produção do viver. Em suas palavras:

A negação dos direitos mais básicos de produção do viver deixa expostas as lacunas de nossos cursos de formação de educadores-docentes dessas infâncias-adolescências. Sem um maior conhecimento dos educandos, dos seus processos mais básicos do viver, sobreviver, os domínios do que e como aprender ficam incompletos. Como dar centralidade ao conhecimento dos educandos e dos processos de produção material da vida nos currículos de formação? (ARROYO, 2013, p. 169)

Podemos afirmar que a convivência com educandos e suas vidas periféricas nos impele a um envolvimento político-ideológico atravessado pelas experiências humanas e pelo respeito à diversidade dos sujeitos, de seus contextos e vivências concretas (ARROYO, 2013, p. 77), bem como ao rompimento da separação entre conhecimentos e experiências sociais.

A reflexão sobre a relação entre as teorias que fundamentam a prática pedagógica no projeto concretiza-se não somente nas reuniões técnicas, mas também na produção científica dos membros da equipe. Assim, uma das consequências do envolvimento acima mencionado é o fato de que temos nos esforçado para divulgar os resultados da pesquisa-ação, discutindo-os com outros membros da comunidade acadêmica da área, através da participação da equipe em eventos científicos e da produção escrita de diferentes gêneros acadêmicos.

Consideramos que, tomando como estratégia de formação de docentes-pesquisadores a participação periférica legítima dos licenciandos na comunidade de práticas acadêmicas, o projeto estimula o letramento acadêmic, na medida em que, gradativamente e sob orientação, desenvolvem a autoria de trabalhos científicos nos quais discutem teórica e metodologicamente diferentes aspectos das práticas compartilhadas pela comunidade Letrajovem.

Como afirmam Lave e Wenger em sua obra inaugural, "Learning involves the whole person; it implies not only a relation to social communities-it implies becoming a full 
participant, a member, a kind of person.” (1991, p.3) Observamos que o movimento centrípeto em direção a tornarem-se membros cada vez mais experientes e habilidosos na comunidade científica da área ocorre na medida em que passam da participação periférica legitimada pelo professor à incorporação das posturas, hábitos, valores e práticas de letramento peculiares a esse grupo, em particular.

$\mathrm{Na}$ interseção entre docência e pesquisa que caracteriza a pesquisa-ação no projeto Letrajovem, os licenciandos constroem sua identidade profissional como professorespesquisadores, movimento em que a aprendizagem situada da escrita acadêmica em eventos científicos reais é fundamental para os iniciantes na comunidade de práticas, por propiciar interações efetivas com membros veteranos.

\section{Referências}

ARROYO, M. G. (2013) Currículo, território em disputa. 3. ed. Petrópolis: Vozes.

BAKHTIN, M. (2011) Estética da criação verbal. 6. ed. São Paulo: Martins Fontes.

BARTON, D. e HAMILTON, M. (2000) Literacy practices. in: Barton, D., Hamilton, M. e Ivanic, R. (Ed.) Situated literacies; reading and writing in context. (pp. 7-15) London and New York: Routledge.

Bordieu, Pierre.(2009) O senso prático. Petrópolis, Rio de Janeiro: Vozes.

BRONCKART, J. P. (2007) Desarrollo del lenguage y didática de las lenguas. Buenos Ayres: Miño y Dávila.

COPE, B.; KALANTZIS, M. Multiliteracies: literacy learning and the design of social futures. London: Routledge, 2000.

'Multiliteracies: New Literacies, New Learning', Pedagogies: An International Journal, Vol.4, 2009, pp.164-195.

FREIRE, P. (1983) Pedagogia do Oprimido. 12. ed. Rio de Janeiro: Paz e Terra.

GEE, J. P. (2008) Social Linguistics and Literacy: Ideology in Discourses. 3. ed. London: Falmer Press.

(2001) Reading as situated language: a sociocognitive perspective. Journal of adolescent \& adult literacy. Newark Delaware, (44) 8, p. 714-725. DOI: 10.1598/JAAL.44.8.3

CHAIKLIN, S. e LAVE, J (Ed.). Understanding Practice: Perspectives on Activity and Context. Cambridge: Cambridge University Press, 1993.

LAVE, J. e WENGER, E.(1991) Situated learning: legitimate peripheral participation. Cambridge: Cambridge University Press.

MENEZES DE SOUZA, L. M. T., \& MONTE MÓR, W. (2006) Orientações Curriculares do Ensino Médio: Línguas Estrangeiras, Linguagens, Códigos e Tecnologias. Brasília: MECSEB.

MORGAN, W. (1997) Critical literacy in the classroom; the art of possible. London and New York: Routledge. 
ONTARIO MINISTRY OF EDUCATION. (2009). Connecting practice and research: Critical literacy guide. Disponível em: http://www.edugains.ca/resourcesLIT/ CoreResources/Critical_Literacy_Guide.pdf.

STREET, B. (2003) What's 'new' in New Literacies Studies? Critical Approaches to Literacy in Theory and Practice. Issues in comparative education. (5) 2, pp. 77-91. Disponível em: http://devweb.tc.columbia.edu/i/a/document/25734_5_2_STREET.pdf 